\title{
Climatic Drivers of Hemispheric Asymmetry in Global Patterns of Ant Species Richness
}

\section{Citation}

Dunn, Robert R., Donat Agosti, Alan N. Andersen, Xavier Arnan, Carsten A. Bruhl, Xim Cerda, Aaron M. Ellison, et al. 2009. Climatic drivers of hemishperic asymmetry in global patterns of ant species richness. Ecology Letters 12(4): 324-333.

\section{Published Version}

http://dx.doi.org/10.1111/j.1461-0248.2009.01291.x

\section{Permanent link}

http://nrs.harvard.edu/urn-3:HUL.InstRepos:2643867

\section{Terms of Use}

This article was downloaded from Harvard University's DASH repository, and is made available under the terms and conditions applicable to Other Posted Material, as set forth at http:// nrs.harvard.edu/urn-3:HUL.InstRepos:dash.current.terms-of-use\#LAA

\section{Share Your Story}

The Harvard community has made this article openly available.

Please share how this access benefits you. Submit a story.

\section{Accessibility}




\section{in Press, Ecology Letters}

\section{Climatic Drivers of Hemispheric Asymmetry in Global Patterns of Ant Species Richness}

Robert R. Dunn ${ }^{1}$, Donat Agosti ${ }^{2}$, Alan N. Andersen ${ }^{3}$, Xavier Arnan ${ }^{3,19}$, Carsten A. Bruhl $^{4}$, Xim Cerda ${ }^{5}$, Aaron M. Ellison ${ }^{6}$, Brian L. Fisher ${ }^{7}$, Matthew C. Fitzpatrick ${ }^{6}$, Heloise Gibb $^{8}$, Nicholas J. Gotelli ${ }^{9}$, Aaron D. Gove ${ }^{1,10}$, Benoit Guenard ${ }^{1}$, Milan Janda ${ }^{11}$, Michael E. Kaspari ${ }^{12}$, Edward J. Laurent ${ }^{1}$, Jean-Philippe Lessard ${ }^{13}$, John T. Longino ${ }^{14}$, Jonathan D. Majer ${ }^{10}$, Sean B. Menke ${ }^{1}$, Terrence P. McGlynn ${ }^{15}$, Catherine L. Parr ${ }^{16}$, Stacy M. Philpott ${ }^{17}$, Martin Pfeiffer ${ }^{18}$, Javier Retana ${ }^{19}$, Andrew V. Suarez ${ }^{20}$, Heraldo L. Vasconcelos $^{21}$, Michael D. Weiser ${ }^{1}$, and Nathan J. Sanders ${ }^{13}$

${ }^{1}$ Department of Biology, North Carolina State University, Raleigh, NC, USA

${ }^{2}$ Dalmaziquai 45, 3005 Bern, Switzerland

${ }^{3}$ CSIRO Sustainable Ecosystems, Tropical Ecosystems Research Centre, Winnellie, NT, Australia

${ }^{4}$ Institute for Environmental Sciences, University Koblenz-Landau, Landau, Germany

${ }^{5}$ Department of Behavioural Ecology, Estación Biológica de Doñana, CSIC, Sevilla, Spain

${ }^{6}$ Harvard Forest, Harvard University, Petersham, MA, USA

${ }^{7}$ Department of Entomology, California Academy of Sciences, San Francisco, CA, USA

${ }^{8}$ Department of Zoology, La Trobe University, Bundoora 3086 Victoria, Australia

${ }^{9}$ Department of Biology, University of Vermont, Burlington, VT, USA

${ }^{10}$ Centre for Ecosystem Diversity and Dynamics in the Department of Environmental Biology, Curtin University, Perth, Australia

${ }^{11}$ Institute of Entomology, Czech Academy of Sciences and Faculty of Science, University of South Bohemia, Ceske Budejovice, Czech Republic

${ }^{12}$ Graduate Program in Ecology and Evolutionary Biology, Department of Zoology, University of Oklahoma, Norman, OK, USA

${ }^{13}$ Department of Ecology and Evolutionary Biology, University of Tennessee, Knoxville, TN, USA

${ }^{14}$ The Evergreen State College, Olympia, WA 98505 USA 
Page 2 of 30

${ }^{15}$ Department of Biology, California State University Dominguez Hills, Carson, CA, USA

${ }^{16}$ Environmental Change Institute, Oxford University Centre for the Environment, Oxford, UK

${ }^{17}$ Department of Environmental Sciences, University of Toledo, Toledo, $\mathrm{OH}$

${ }^{18}$ Institute of Experimental Ecology, University of Ulm, Albert Einstein Allee 11, 89069 Ulm, Germany

${ }^{19}$ Unit of Ecology and Center for Ecological Research and Forestry Applications (CREAF), Autonomous Univ. of Barcelona, Bellaterra (Barcelona), Spain

${ }^{20}$ Department of Entomology and Department of Animal Biology, University of Illinois, Urbana, Illinois 61801 USA

${ }^{21}$ Institute of Biology, Federal University of Uberlândia (UFU), CP 593, Uberlândia, MG, Brazil 
Page 3 of 30

Running title: Latitudinal asymmetry in ant diversity

Key words: biodiversity, Eocene, Formicidae, latitudinal gradient, climate change 
Page 4 of 30

\section{ABSTRACT (153 words)}

Although many taxa show a latitudinal gradient in richness, the relationship between latitude and species richness is often asymmetrical between the northern and southern hemispheres. Here we examine the latitudinal pattern of species richness across 1003 local ant assemblages. We find latitudinal asymmetry, with southern hemisphere sites being more diverse than northern hemisphere sites. Most of this asymmetry could be explained statistically by differences in contemporary climate. Local ant species richness was positively associated with temperature, but negatively (although weakly) associated with temperature range and precipitation. After contemporary climate was accounted for, a modest difference in diversity between hemispheres persisted, suggesting that factors other than contemporary climate contributed to the hemispherical asymmetry. The most parsimonious explanation for this remaining asymmetry is that greater climate change since the Eocene in the northern than in the southern hemisphere has led to more extinctions in the northern hemisphere with consequent effects on local ant species richness. 


\section{INTRODUCTION}

It is well documented that species richness varies with latitude (Willig et al. 2003; Currie et al. 2004b; Mittelbach et al. 2007). However, there is much debate as to the underlying causes of this variation (e.g., Willig et al. 2003, Dunn 2008). Broad-scale patterns of species richness are often correlated with contemporary climate (Gaston 1996; Hawkins et al. 2003; Brown et al. 2004; Hawkins et al. 2007). Yet other factors such as disturbance, history, climatic history, and geography can affect patterns of richness in addition to or independent of the effects of contemporary climate. If this is the case, then richness should differ among regions after differences in contemporary climate are accounted for. Conversely, richness should vary little among regions (Qian et al. 2005) and hemispheres (Chown et al. 2004) once contemporary climate is accounted for, if contemporary climate alone is a sufficient correlate of richness.

Climate-richness relationships often vary between hemispheres (Gaston 1996; Chown et al. 2004), biogeographic regions (Ricklefs et al. 2004) and habitats (Hurlbert 2004). Additionally, species richness can vary strongly between regions that have similar climates (Morton \& Davidson 1988), a fact recognized at least since Darwin's travels to Tierra del Fuego (in "Recapitulation" at the end of chapter six; Darwin 1845). Numerous taxa show hemispheric asymmetries in latitudinal diversity gradients: seed plants (Woodward 1987), trees (Burns 2007), deep-sea benthos (Rex et al. 1993), mammals (Gaston et al. 1995), termites (Eggleton et al. 1994), birds (Blackburn \& Gaston 1996), spiders (Platnick 1991), and triatomids (Rodriguero \& Gorla 2004).Yet, the generality 
Page 6 of 30

and causes for such asymmetries remain scarcely better studied than they were in 1845 (Chown et al. 2004).

Numerous historical explanations for differences in richness between the southern and northern hemispheres can be envisioned. Specific regions, such as Australia in the southern hemisphere, may be more diverse than expected due to historical idiosyncrasies, such as the presence of rapidly diversifying lineages. The northern hemisphere could also be less diverse than the southern hemisphere because of differences in recent glacial history (Hawkins \& Porter 2003; Svenning \& Skov 2005; Montoya et al. 2007). Alternatively, climate change since the origin of particular clades may have been less in the southern than in the northern hemisphere (Wilf et al. 2005), leading to reduced rates of extinction in the southern hemisphere (Rohde 1999). Finally, contemporary climatic conditions, to the extent that they are also asymmetric, might account for the hemispheric asymmetry in richness (Chown et al. 2004). Darwin, for example, attributed the greater diversity of life forms in the southern hemisphere to the more "equable climate" (Darwin 1845). Few studies to date have considered which combination of historical and contemporary factors best accounts for hemispheric asymmetries in diversity.

Additionally, most studies of latitudinal gradients in species richness (and largescale patterns of richness more generally) have relied on data generated from the overlap of species ranges or interpolated richness between localities rather than actual site estimates of richness (Jetz \& Rahbek 2002; Hawkins et al. 2003) or lists of regional flora (Kreft \& Jetz 2007). Large-grain interpolated richness sets the maximum species pool for local assemblages, but does not necessarily reflect measured richness at local scales relevant to ecological processes and conservation goals. For example, hemispheric 
asymmetries present at large-grains might disappear at the local grains, where interspecific interactions and climate act to filter the regional species pool. However, few global analyses have investigated whether, and how consistently, contemporary climatic factors influence spatial patterns of richness within local communities (Gentry 1988; Currie et al. 2004a; Pautasso \& Gaston 2005; Burns 2007). To our knowledge, there are no published studies of whether there is a latitudinal asymmetry in local richness of animals, though it was at just such a local scale that the pattern was first suggested (Darwin 1845).

Here we use data from 1003 local ant communities collected over six continents and a broad spectrum of habitat types and climatic conditions to examine latitudinal asymmetry in local ant richness. We examine the effect of several climatic variables (temperature, precipitation and temperature range), and hemisphere (north-south) on local ant species richness. We also consider three kinds of "history" and their potential influence on gradients in ant diversity: regional history, disturbance history, and climate change history (the net difference between Eocene and modern climates). For regional history, we first consider one of the few a priori predictions for which regions might be more diverse than expected on the basis of climate. It has been suggested that unique conditions and idiosyncrasies of arid Australia have led to exceptional species richness there (Andersen 2007), and this might result in higher southern hemisphere richness overall. For disturbance history, we examine whether disturbance by one kind of historic climate change, glaciation, has influenced global patterns of diversity. Finally, we consider whether one aspect of climatic stability, the change in climate between the Eocene (when most ant genera evolved) and today, may account in part for contemporary 
Page 8 of 30

richness patterns. Greater change in climate since the Eocene diversification could have led, for example, to larger numbers of extinctions for a given climate and hence lower contemporary richness. Our results suggest that contemporary climate and changes in climate since the Eocene may together account for much of the hemispheric asymmetry in the richness of ants in local assemblages.

\section{MATERIALS AND METHODS}

\section{Compiling the global database}

As part of a larger project (Dunn et al. 2007), we compiled species richness data from local ant communities from as many sites as possible. Most of our samples consist of primary data collected in the authors' own field work. In addition, we exhaustively searched Web of Science, Formis (http://www.ars.usda.gov/saa/cmave/ifahi/formis) and GoogleScholar for published data sets (web search on January 31, 2006). All studies included in this analysis met the following criteria: $(i)$ the ground-foraging ant community was sampled using standardized (though not identical) field methods, $(\mathrm{ii})$ the area sampled was $\leq 1$ ha, (iii) the sampling was not trophically or taxonomically limited (e.g., the study was not focused only on seed harvesting ants), (iv) sampling occurred on mainland habitats, not islands, and $(v)$ study sites were minimally disturbed natural habitat. To minimize bias due to differences in sampling protocols among studies, we included only studies that employed more than 15 samples within a site and used either pitfall and/or litter sampling. If the same site was sampled multiple times, we averaged the data across sample dates to obtain a single species richness value for that site. We repeated the analyses using the maximum estimate of species richness for sites with 
multiple samples, and the results were not qualitatively different. Therefore, we report results using only the average number of species per site. Because we were interested in characterizing local communities, we excluded studies that provided only regional species lists for large areas or politically defined regions (e.g., the ants of Colorado). Because species density is sensitive to both the number of individuals and the number of samples collected, sampling differences potentially contribute to variation in species counts among sites. We controlled for sample number in two ways. First, we included Ztransformed sample number as a potential predictor variable in all regression models. Sites might be expected to be measured as more diverse if they were better sampled. Such bias would be more problematic if it were systematic with regard to the environmental variables considered. In a stepwise regression, however, with sample number as the dependent variable and temperature, precipitation, temperature range and hemisphere as independent variables, only precipitation was correlated with sample number and weakly at that $\left(\mathrm{p}<0.001, \mathrm{R}^{2}=0.045\right)$. Second, we included a categorical variable that denoted whether the sample was from pitfall traps or leaf litter. Finally, we repeated the analyses on a subsample of sites with large sample sizes ( $\mathrm{n}>50$ samples). Qualitative results were the same for all of these various subsets of the data, so we report only the results using the sample number and type (leaf-litter vs pitfall trap) as predictor variables. As an additional safeguard for the effect of sampling differences among the studies, we tested the correlation between local area sampled and local species richness. However, these two variables were poorly correlated in the studies with information on sample area $(\mathrm{n}=$ $550, \mathrm{R}^{2}=0.02, \mathrm{p}=0.08$ ), so we did not include sample area in subsequent analyses.

\section{Climatic variables}


We selected two climatic variables for regression analysis that are consistently correlated with species richness in numerous studies: mean annual temperature and annual precipitation. These correlations are strong for ants (Kaspari et al. 2000; Majer et al. 2001; Kaspari et al. 2004; Sanders et al. 2007) as well as for many other taxa (Hawkins et al. 2003), and are important elements of the temperature-dependent kinetics theory (Rohde 1992), species energy theory (Kaspari et al. 2000), and limitations imposed by water balance (Hawkins et al. 2003). Although there are biological reasons why different temperature variables might affect ant communities differently (minimum temperatures might influence mortality and extinction, for example), both minimum and maximum temperatures are well correlated with mean temperatures $\left(\mathrm{r}^{2} \min =0.78, \mathrm{r}^{2} \max =0.62\right)$. As such, we chose mean annual temperature because it is the measure of temperature most often considered. In addition, we considered a measure of temperature variability within the year, temperature range ( $\max$ temp - min temp), which is correlated with mean temperature $\left(\mathrm{r}^{2}=0.35\right)$ and is a measure of the range of temperatures experienced by organisms at a site through the year. Temperature variability, and in particular temperature range, has long been thought to be important in understanding differences among hemispheres (Darwin 1845), both with regard to diversity and with regard to attributes of ecological communities more generally (Ting et al. 2008). We initially used the interaction of annual precipitation and mean annual temperature as a third predictor variable. However, this interaction was never significant in any model and so is not further considered. Contemporary environmental variables (Table 1) are from the WorldClim database (Hijmans et al. 2004) at a spatial resolution of $1 \mathrm{~km}$ and were extracted using ArcGIS (ESRI 2006). A resolution of $1 \mathrm{~km}$ means that our environmental 
data integrate the conditions specifically at the site at which ants were sampled and the surrounding environment. The magnitudes of the environmental variables, sample number and diversity estimates were standardized by $Z$-score transformation $[Z(x i)=(x i-$ $\operatorname{mean}(x)) / \operatorname{sd}(x)]$

In addition to contemporary climate, we considered the glacial history of sites and temperature change since the Eocene. On the basis of models of the distribution of glaciers during the last glacial maximum, sites were coded as either glaciated or nonglaciated (data from Ehlers \& Gibbard 2004). Globally averaged mean annual temperatures in the Eocene were, on average, as much as $10^{\circ} \mathrm{C}$ warmer than contemporary temperatures (Zachos et al. 2001). We used data from Greenwood and Wing (1998) on differences between contemporary and Eocene temperatures.

\section{Analyses}

We used general linear models with three continuous variables (temperature and precipitation and temperature range) and one categorical variable, hemisphere (northern or southern) to compare two initial regression models. Those two models were: (1) climate variables only; and (2) climate variables and hemisphere. Because the northern and southern hemisphere differed even once climate was accounted for statistically, we then explored three aspects of history that might explain such differences. First, we repeated our analyses, but with Australia considered separately (model 3) to understand whether the southern hemisphere was more diverse simply because Australia is more diverse, in essence testing for a specific effect of regional history. Second, we considered a disturbance history model (model 4) in which whether or not a site was glaciated during 
Page 12 of 30

the glacial maximum was included as a categorical variable. General linear models were fit with JMP software (SAS, 2008). Model fit was evaluated with Akaike's Information Criterion (AIC) scores, where AIC is calculated as: $A I C=n \ln \left(\frac{S S E}{n}\right)+2 p$. Low AIC scores indicate better fit. The absolute value of the AIC score is not important, but AIC differences reflect the relative support for different models (Burnham \& Andersen 2002).

Finally, we used a general linear model (GLM) to consider differences between spatial patterns of temperature today and during the Eocene. In the GLM, mean annual temperature was the dependent variable, and era (contemporary vs Eocene), hemisphere and their interaction were the independent variables. While the ideal approach would be to include some measure of climate change through time at each of our sites in our GLM models, present data do not permit such an analysis, nor are they ever likely to. Latitudes covered both by our database and Greenwood and Wing (1998) and considered in this study were 22 to 45 degrees in the southern hemisphere and 36 to 51 degrees in the northern hemisphere.

We did not use spatial regressions for two reasons. First, it remains difficult to interpret with certainty which models to use and how to interpret the coefficients generated by the models (Bini et al., In press). Second, such models work best for approximately gridded data, and the data analyzed here are from clusters of sites within continents. Using standard spatial statistics for these data is difficult because of the huge distances between some sites that occur in different continents.

\section{RESULTS}


Page 13 of 30

\section{Global Patterns}

Species richness of ground-foraging ants per site varied from 0 to 184 species (Figure 1). Ant species richness decreased with increasing latitude in both the northern hemisphere $\left(\mathrm{R}^{2}=0.35, P<0.0001\right.$, Est. $\left.=-0.04\right)$ and the southern hemisphere, though only very weakly in the latter $\left(\mathrm{R}^{2}=0.09, P<0.0001\right.$, Est. $=0.02$; Figure 1, Figure $\left.2 \mathrm{c}\right)$. Dunn et al . (in press) found similar patterns when they examined generic data compiled at the regional grain for different political regions (reproduced in Figure 2d). Temperature and precipitation were both greater in the southern than in northern hemisphere for the same latitude across the sampled sites (Figure 2a). Temperature range showed a more complex pattern of variation with latitude (Figure $2 b$ ).

\section{The Models}

Model 1: Climatic correlates - Ant species richness was positively correlated with temperature, and negatively correlated with precipitation and temperature range (Table 1). In all models, ant species richness increased with sample number and was higher for samples from leaf-litter than from pitfall traps, as has also been found in local comparisons of the two methods (Fisher 1996). Together, climate and sampling differences among sites accounted for $49 \%$ of variation in ant species richness.

Model 2: Climatic correlates + Hemisphere - Hemisphere accounted for an additional $3 \%$ variation left unexplained by mean annual temperature, precipitation and temperature range, with the southern hemisphere being more diverse than the northern hemisphere overall (Table 1; Figure 3a). AIC values were lower for the model that included both 
Page 14 of 30

climatic correlates and hemisphere than for the model that did not include hemisphere as a factor.

Model 3: Climatic correlates + Hemisphere + Australia - When the southern hemisphere was divided into two regions, Australia and elsewhere (Africa + South America), results were similar to those when southern hemisphere regions were pooled. Both southern hemisphere regions (Australia and non-Australia) were more diverse than the northern hemisphere. AIC values for the model that divided the southern hemisphere into Australian and non-Australian sites were slightly lower than for the model in which the world was divided simply into the northern and southern hemisphere. However, treating Australia separately accounted for no additional variation in ant species richness (Table 1).

Model 4: Climatic correlates + Glacial history - The glacial history of sites (whether or not they had been glaciated during the most recent glacial maximum), explained no more variation than did a model which including only contemporary climate and had a higher AIC score (Table 1).

Contemporary and Eocene temperatures - If hemispheric asymmetries in diversity were explained in part by hemispheric asymmetries in climate change since the Eocene (when much of ant diversification occurred), the southern hemisphere needs to have experienced less net change in climate since the Eocene than has the northern hemisphere. For the sites considered, the difference between Eocene and contemporary temperatures is much more pronounced in the northern than in the southern hemisphere (Figure 3b). In our model (with hemisphere, era and their interaction as independent variables), era $(P=$ 
Page 15 of 30

0.019), hemisphere $(P<0.0001)$ and their interaction $(P=0.009)$ were all significantly associated with mean annual temperature (whole model; $\mathrm{R}^{2}=0.51, \mathrm{SS}=302.7$ ). The decrease in temperature (from Eocene to today) was greater in the northern than in the southern hemisphere, as would be expected if climate-change induced extinctions were to responsible for the differences in diversity between the two hemispheres.

\section{DISCUSSION}

Although the latitudinal gradient in species richness is among the best-known and moststudied patterns in ecology, large-scale comparisons of local communities remain scarce (Willig et al. 2003; Hillebrand 2004). For ground-foraging ants, we found that there is a latitudinal gradient in local species richness for the globe as a whole. That latitudinal gradient is not, however, symmetrical about the equator. We found higher species richness in the southern compared with northern hemisphere, and the latitudinal gradient was far weaker in the southern hemisphere.

Contemporary climate, together with one measure of sampling effort, accounts statistically for approximately half of the variation in the number of ant species in local communities. Hemispherical asymmetry in species richness could therefore be due simply to hemispheric differences in contemporary climate. Yet even when we removed the effects of contemporary climate and sampling effort on local ant species richness, local ant species richness was still higher in the southern hemisphere than the northern hemisphere. 
If species richness is primarily influenced by recent or contemporary climate then higher ant species richness should be expected in the southern hemisphere, depending on the relative importance of different environmental variables. Temperature and precipitation, for example, are both higher in the southern hemisphere as is within-year temperature range. Our environmental model (in which hemisphere was excluded as a variable) predicted higher species richness in the southern hemisphere, largely as a consequence of the higher temperatures of the southern hemisphere for a given latitude. Ants are typically thermophilic and so the hemispheric asymmetry in temperature should lead to hemispheric asymmetry in species richness. Temperature likely influences ant diversity in a number of ways. Low minimum temperatures may influence rates of ant mortality and ultimately extinction rates. High maximum and mean temperatures may allow ants to forage more and harvest more energy and in doing so reduce extinction rates (Sanders et al. 2007). While contemporary temperature and other climate variables could not have driven historic patterns of ant diversification, species ranges may have shifted so that the current patterns integrate the historical effects of temperature on diversification.

We expected a priori that the relationship between temperature and species richness would be positive in both the northern and southern hemispheres - an expectation supported by our findings. Indeed our environmental model (in which hemisphere was excluded as a variable) predicted higher species richness in the southern hemisphere, largely as a consequence of the higher temperatures of the southern hemisphere for a given latitude. This finding reconciles well with the observation that for a given latitude, northern hemisphere lineages of a range of insect taxa are more likely to 
have adaptations for avoiding long periods of cold, whereas southern hemisphere species are more likely to have adaptations for tolerating short periods of cold (Chown et al. 2004; Sinclair \& Chown 2005). In essence Darwin's model in which the higher diversity of the southern hemisphere was associated with its more favorable climate (Darwin 1845) was supported by our results.

Just which climate variables were correlated with richness and the direction of that correlation, however, differed for ants relative to other, better-studied taxa. In particular, precipitation was negatively (albeit weakly) correlated with ant richness. A negative relationship between species richness and precipitation is uncommon in studies of species richness, particularly in the southern hemisphere, where it is thought that water is the most limiting climatic variable (Hawkins et al. 2003). In contrast to birds (Davies et al. 2007), amphibians (Buckley \& Jetz 2007), or plants (Kreft \& Jetz 2007), species richness of ground-foraging ants is relatively higher in the dry, hot regions of the world. What allows ants to be diverse where even other thermophilic taxa are not is an important, but unresolved, question.

It may be that overall species richness of ants (ground foraging and arboreal) is positively correlated with precipitation. For example, in Australia canopy ant species richness is highest in the wettest habitats (Majer et al. 2001), where ground-foraging ant species richness is quite low (Shattuck 1999). The same could be true elsewhere, but Australia is the only region where the correlates of canopy ant diversity have been considered. Interestingly, one of the observations that initially led Darwin to notice the hemispheric asymmetry was the greater prevalence and diversity of canopy plants in the southern than in the northern hemisphere for a given latitude (Darwin 1845). Whether the 
same might be true of ants and other canopy insects deserves study. Similarly, while our data on ground-foraging ant communities are extensive, regions remain poorly sampled, including much of Africa and northern Asia. Samples from such areas would be very useful in better understanding the correlates and even the causes of patterns in ant diversity.

Even when we removed the effects of contemporary climate and sampling effort on local ant species richness, local ant species richness was still higher in the southern hemisphere than the northern hemisphere. Such differences were echoed in other comparisons of sites across regions. For example, the richness of local litter-ant diversity in forests has been found to be lower in North America than in South America once temperature was accounted for (Kaspari et al. 2004).

Several explanations have been proposed that might account for higher local ant species richness in the southern hemisphere independent of differences in temperature, precipitation, and temperature range. It has been suggested that local tree species richness is higher in the southern hemisphere in part due to higher tree density in the southern hemisphere (Burns 2007). Similarly, ant density might also help explain ant species richness as ant density and species richness are well correlated at a variety of sampling grains (Kaspari et al. 2003; Sanders et al. 2007). However, such a relationship begs the question of why ant, or tree, density might be higher in the southern hemisphere. Alternatively, other climatic or abiotic factors (including features such as soil nutrient concentrations; McGlynn et al. 2007) not considered could generate asymmetry in local ant richness if those conditions differ systematically between hemispheres. Yet our analysis included the three key variables (temperature, precipitation, and temperature 
Page 19 of 30

range) associated with hemispheric differences in species richness (Chown et al. 2004) and consistently correlated with ant species richness in many studies (Kaspari et al. 2000; Kaspari et al. 2003; Sanders et al. 2007).

Perhaps the most interesting possibility is that differences between the southern and northern hemispheres are due to differences between recent climate histories (e.g., glaciations, differences between climates at the time of ant diversification and contemporary climates, or regional idiosyncrasies). Glacial cycles have had a much stronger influence in the northern hemisphere than in the southern hemisphere. For northern hemisphere trees (Montoya et al. 2007) and amphibians and reptiles (Araujo et al. 2008), recent studies have linked contemporary patterns of species richness to the time since sites were glaciated. In contrast, contemporary climate accounts for most of the variation in species richness of more vagile taxa such as birds and mammals (Hawkins \& Porter 2003), as might be expected if these more vagile taxa are in better equilibrium with the current environment. Given that many ant lineages are likely to have poor dispersal abilities (Peeters \& Ito 2001), it seems conceivable that glacial history or more generally, the severity of climatic cycles could account for some of the hemispheric asymmetry in ant species richness. However, whether or not a site was glaciated did not help explain its contemporary local ant diversity. Similarly, including another regional effect, whether or not a site was in Australia, as a variable did not explain additional variation in species richness, despite the unique geological history of Australia. Though other regions in the southern hemisphere might have histories as unique as Australia's, the extremely high local ant diversity (Morton \& Davidson 1988, Andersen 2007) has long been highlighted and represented a useful a priori hypothesis to test. 
Page 20 of 30

Alternatively, species richness might be influenced by the stability of climates in different regions, particularly between the Eocene, when ant diversification was apparently most rapid (Brady et al. 2006; Moreau et al. 2006), and the present day. In comparing Eocene climate data (Greenwood \& Wing 1995) to the temperature data from the sites in our database, we found that while southern hemisphere temperatures are similar today to those during the Eocene, the northern hemisphere sites are much cooler. These results are reconcilable with the idea that the stability of the southern hemisphere sites has contributed to their greater diversity.

When we re-plotted ant generic diversity (number of genera) from a recent study (Dunn et al. in press), where the sampling grain was political regions, generic diversity showed latitudinal asymmetries similar to those for local richness (if anything, more pronounced; Figure 2d), suggesting the asymmetry dates at least to the time of the radiation of ant genera. Because most of the new cladogenesis that occurred during the Eocene was in clades now regarded as genera, we might expect ant generic diversity to show the effects of historical climate more strongly than does ant species diversity. However, generic and species diversity of ants are often well-correlated in space (e.g., Dunn et al. in press, but see Andersen 1995), such that the effect of Eocene temperatures on radiation might influence diversity patterns at both taxonomic levels. For climatic stability (or lack thereof) to have contributed to the hemispheric asymmetry, the difference between contemporary and Eocene temperatures would need to be greater in the northern hemisphere than in the southern hemisphere.

To date, fossil data, although incomplete, also appear to indicate more extinctions from the northern than the southern hemisphere for ants. Many ant lineages once found in 
Page 21 of 30

northern hemisphere forests and grasslands are now restricted to the tropical reaches of the northern hemisphere (Pseudomyrmex and Tetraponera), or are extinct entirely from the northern hemisphere (Myrmeciinae;(Archibald \& Greenwood 2005)).

Anonychomyrma is known from Eocene Baltic and Belarus amber, but is now found only in Australia, Indonesia and Papua New Guinea. Podomyrma is known from Sicilian amber, but is now restricted to Australia and Papua New Guinea, including the coolest regions of Australia (Shattuck 1999). Pseudolasius is known from the Baltic Amber (Wheeler 1915), but is now found only in the tropics of the southern hemisphere. We are unable to find any counter examples of genera known from fossils in the southern hemisphere but now restricted to the northern hemisphere (indeed, comparatively few ant lineages are restricted to the northern hemisphere).

In conclusion, our results highlight the strong correlation between contemporary climate and the number of species co-occurring in a local community. To a greater extent than for other taxa that have been studied to date, ground-foraging ants are diverse in hot, dry habitats, leading to a hemispheric asymmetry in their patterns of local richness. However, the southern hemisphere remains more diverse than the northern hemisphere even after contemporary climate is controlled for, and this can be accounted for by greater climatic stability, and therefore fewer extinctions, in the south compared with the north. In sum, though contemporary climate is often invoked as a primary driver of broad-scale patterns of diversity, our results suggest that historical climate and, in particular, changes in climate can no longer be overlooked.

\section{ACKNOWLEDGEMENTS}


Page 22 of 30

This work was supported by a DOE-NICCR grant to RR Dunn and NJ Sanders and in addition a DOE-PER grant DE-FG02-08ER64510 to RR Dunn, NJ Sanders, AE Ellison and NJ Gotelli. Original data collection at respective field sites was sponsored by diverse funding agencies from many different countries. JTL was supported by the National Science Foundation grant DEB-0640015 during the writing of this manuscript. 
Table 1. Regression models for local ant species richness for the (1) climate, (2) climate + hemisphere, (3) climate + hemisphere (Australia treated separately) and (4) climate + glacial history. The dependent variable in all cases is local ground-foraging ant species richness. In sample type, $1=$ litter, $p=$ pitfall. $+/$ - indicates whether the coefficient is positive or negative. $\mathrm{R}^{2}$ and AIC values correspond to the values for each model. Bolded coefficients indicate significance. MAT $=$ Mean annual temperature. Int. $=$ intercept. In model 3, the two comparisons are for Australia vs the rest of the southern hemisphere (Au/S, not significant) and the rest of the southern hemisphere vs the northern hemisphere $(\mathrm{N} / \mathrm{S}, \mathrm{p}<0.001)$.

\begin{tabular}{|c|c|c|c|c|c|c|c|c|c|c|c|c|}
\hline MODEL & Int. & MAT & Precip. & $\begin{array}{l}\text { Temp. } \\
\text { range }\end{array}$ & $\begin{array}{l}\text { Sample } \\
\text { (N) }\end{array}$ & $\begin{array}{l}\text { Sample } \\
\text { type }(1, p)\end{array}$ & Hemi. & Aus. & Glacial & AIC & $\mathrm{R}^{2}$ & $\mathrm{DF}$ \\
\hline 1) Climate & 0.43 & 0.51 & -0.13 & -0.10 & 0.34 & 0.37 & & & & -719.2 & 0.49 & 990 \\
\hline $\begin{array}{l}\text { 2) Climate }+ \\
\text { hemisphere }\end{array}$ & 0.47 & 0.41 & -0.07 & NS & 0.35 & -0.39 & -0.21 & & & -775.0 & 0.52 & 989 \\
\hline $\begin{array}{l}\text { 3) Climate }+ \\
\text { hemisphere (Aus. } \\
\text { separate) }\end{array}$ & 0.47 & 0.44 & -0.066 & NS & 0.33 & -0.36 & & & & -778.3 & 0.52 & 989 \\
\hline $\begin{array}{l}\text { 4) Climate }+ \\
\text { glacial history }\end{array}$ & 0.55 & 0.55 & -0.16 & -0.14 & 0.32 & -0.38 & & & 0.15 & -726.7 & 0.49 & 989 \\
\hline
\end{tabular}


Figure 1. Species richness of sites considered in this study. Warmer colors and larger circles are more diverse. Each point indicates one site. Sites are divided into richness quintiles. Black line indicates the equator and hence divides the northern and southern hemispheres.

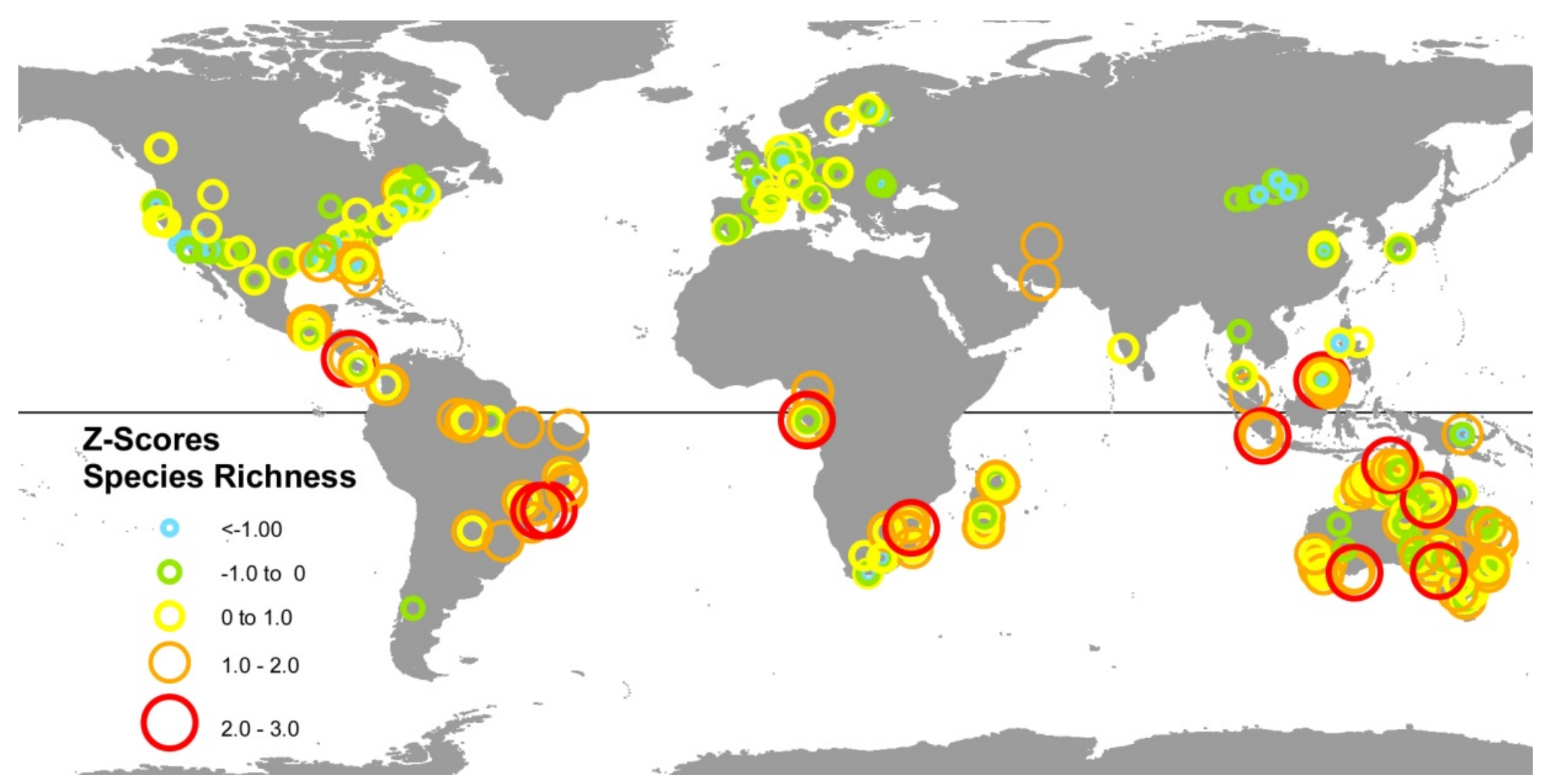


Figure 2. Annual precipitation and mean annual temperature (a), temperature range (b), local species richness of ants (c) and regional richness of ant genera (d) as a function of latitude. Patterns of generic richness are plotted for comparison. Generic richness estimates are modified from Dunn et al. (in press) and are derived from species and genus lists from countries and smaller political regions.

4 They are presented for comparison only. Negative latitudes indicate the southern hemisphere.
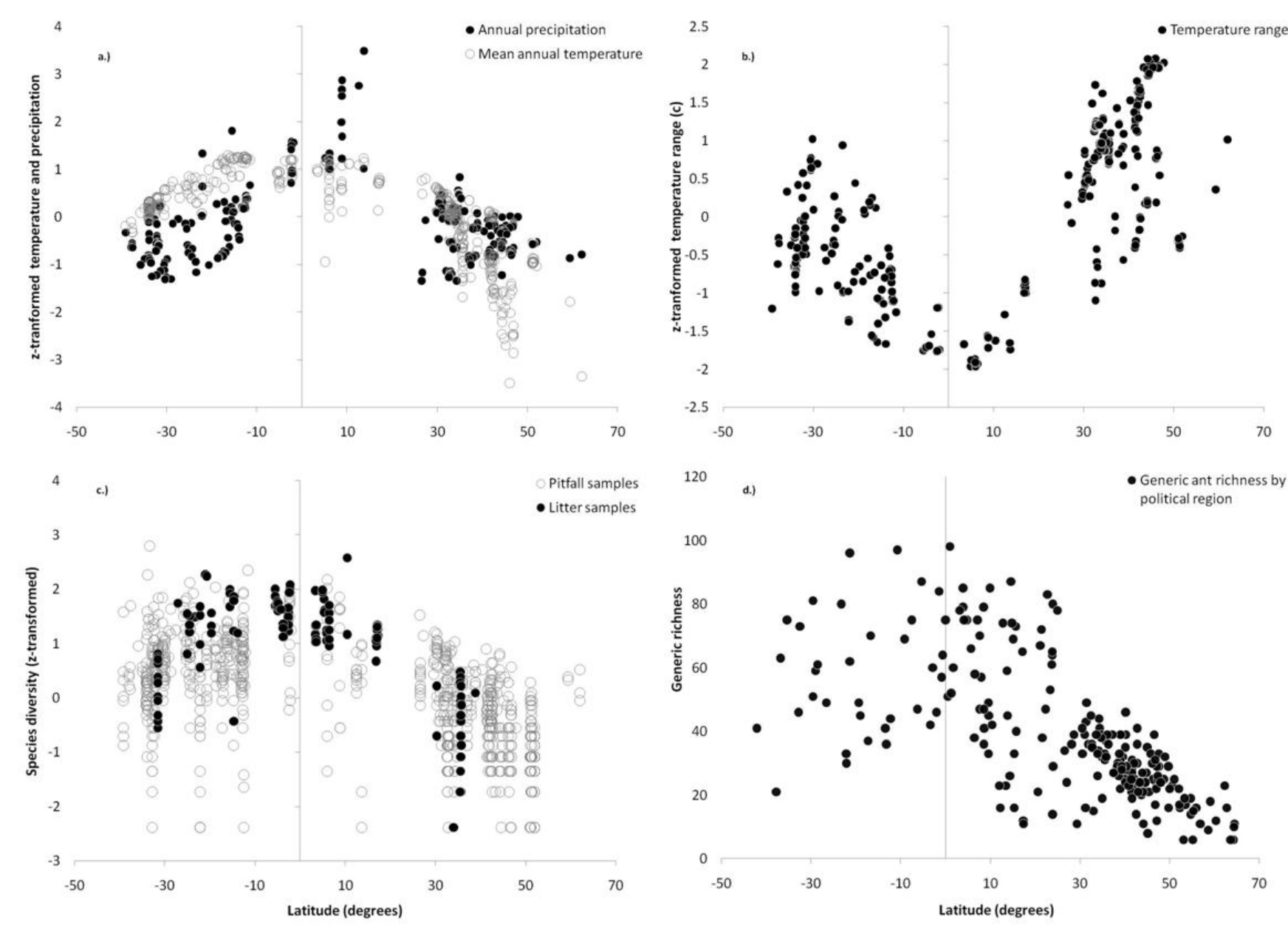
6 Figure 3. Residuals of model 1 (climate variables only) plotted by hemisphere for all data (a) and average mean annual temperature 7 fore the southern and northern hemispheres on the basis of the contemporary and Eocene data. Bars $=$ standard error of the mean.
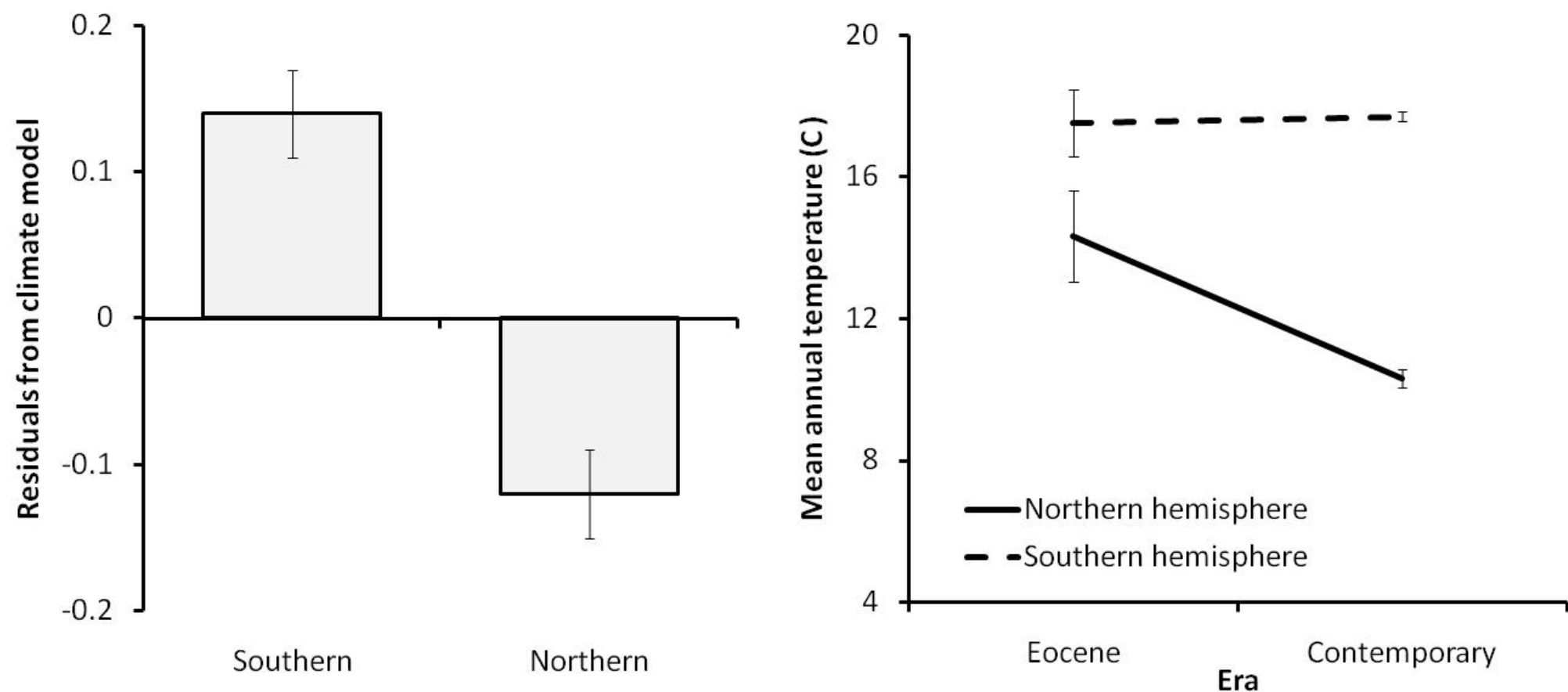


\section{REFERENCES}

Andersen, A.N. (1995) Measuring more of biodiversity: genus richness as a surrogate for species richness in Australian ant communities. Biological Conservation 73, 3943.

Andersen A.N. (2007). Ant diversity in arid Australia: a systematic overview. In: Advances in Ant Systematics (Hymenoptera: Formicidae): Homage to E. O. Wilson-- 50 Years of Contributions. (eds. Snelling RR, B.L. Fisher \& Ward PS). Memoirs of the American Entomological Institute.

Araujo M.B., Nogues-Bravo D., Diniz-Filho J.A.F., Haywood A.M., Valdes P.J. \& Rahbek C. (2008). Quaternary climate changes explain diversity among reptiles and amphibians. Ecography, 31, 8-15.

Archibald S.B. \& Greenwood D.R. (2005). The Okanagan Highlands: Eocene biota, environments, and geological setting, southern British Columbia, Canada and northeastern Washington, USA. Canadian Journal of Earth Sciences, 42, 111114.

Blackburn T.M. \& Gaston K.J. (1996). Spatial patterns in the species richness of birds in the New World. Ecography, 19, 369-376.

Brady S.G., Schultz T.R., Fisher B.L. \& Ward P.S. (2006). Evaluating alternative hypotheses for the early evolution and diversification of ants. Proceedings of the National Academy of Sciences of the United States of America, 103, 18172-18177.

Brown J.H., Gillooly J.F., Allen A.P., Savage V.M. \& West G.B. (2004). Toward a metabolic theory of ecology. Ecology, 85, 1771-1789.

Buckley L.B. \& Jetz W. (2007). Environmental and historical constraints on global patterns of amphibian richness. Proceedings of the Royal Society B-Biological Sciences, 274, 1167-1173.

Burnham K.P. \& Andersen D.R. (2002). Model selection and multimodel inference: a practical-theoretic approach.

Burns K.C. (2007). Is tree diversity different in the Southern Hemisphere? Journal of Vegetation science, $18,307-312$.

Chown S.L., Sinclair B.J., Leinaas H.P. \& Gaston K.J. (2004). Hemispheric asymmetries in biodiversity - A serious matter for ecology. PLoS Biology, 2, 1701-1707.

Currie D.J., Mittelbach G.G., Cornell H.V., Field R., Guegan J.F., Hawkins B.A., Kaufman D.M., Kerr J.T., Oberdorff T., O'Brien E. \& Turner J.R.G. (2004a). Predictions and tests of climate-based hypotheses of broad-scale variation in taxonomic richness. Ecology Letters, 7, 1121-1134.

Currie D.J., Mittelbach G.G., Cornell H.V., Field R., Guegan J.F., Hawkins B.A., Kaufman D.M., Kerr J.T., Oberdorff T., O'Brien E.M. \& Turner J.R.G. (2004b). Predictions and tests of climate-based hypotheses of broad-scale variation in taxonomic richness. Ecology Letters, 7, 1121-1134.

Darwin C.R. (1845). Journal of researches into the natural history and geology of the countries visited during the voyage of H.M.S. Beagle round the world.... 2nd ed. edn. John Murray, London.

Davies R.G., Orme C.D.L., Storch D., Olson V.A., Thomas G.H., Ross S.G., Ding T.S., Rasmussen P.C., Bennett P.M., Owens I.P.F., Blackburn T.M. \& Gaston K.J. 
Page 28 of 30

(2007). Topography, energy and the global distribution of bird species richness.

Proceedings of the Royal Society B-Biological Sciences, 274, 1189-1197.

Dunn R.R., Sanders N.J., Fitzpatrick M.C., Laurent E., Lessard J.-P., Agosti D., Andersen A.N., Bruhl C., Cerda X., Ellison A.M., Fisher B.L., Gibb H., Gotelli N.J., Gove A., Guenard B., Janda M., Kaspari M., Longino J.T., Majer J., McGlynn T.P., Menke S.B., Parr C.L., Phillpott S.M., Pfeiffer M., Retana J., Suarez A.V. \& Vasconcelos H.L. (2007). Global ant (Hymenoptera: Formicidae) biodiversity and biogeography - a new database and its possibilities. Myrmecological News, 10, 77-83.

Dunn R.R., Weiser M.D., Guenard B. \& Sanders N.J. (in press). Geographic gradients in the diversity, abundance, size, and ecological consequences of ants. In: Ant Ecology

(eds. Lach L, C. Parr \& Abbot K).

Eggleton P., Williams P.H. \& Gaston K.J. (1994). Explaining global termite diversity productivity or history. Biodiversity and Conservation, 3, 318-330.

Ehlers J. \& Gibbard P. (2004). Quartenary glaciations - Extent and chronology. Elsevier.

Fisher B.L. (1996). Ant diversity patterns along an elevational gradient in the Reserve Naturelle Integrale d'Andringitra, Madagascar. Fieldiana Zoology, 85, 93-108.

Gaston K.J. (1996). Biodiversity - Latitudinal gradients. Progress in Physical Geography, 20, 466-476.

Gaston K.J., Williams P.H., Eggleton P. \& Humphries C.J. (1995). Large scale patterns of biodiversity: spatial variation in family richness. Proceedings of the Royal Academy of London B, 260, 149-154.

Gentry A.H. (1988). Changes in plant community diversity and floristic composition on environmental and geographical gradients. Annals of the Missouri Botanical Garden, 75, 1.

Greenwood D.R. \& Wing S.L. (1995). Eocene continental climates and latitudinal temperature-gradients Geology, 23, 1044-1048.

Hawkins B.A., Diniz J.A.F., Bini L.M., Araujo M.B., Field R., Hortal J., Kerr J.T., Rahbek C., Rodriguez M.A. \& Sanders N.J. (2007). Metabolic theory and diversity gradients: Where do we go from here? Ecology, 88, 1898-1902.

Hawkins B.A., Field R., Cornell H.V., Currie D.J., Guegan J.F., Kaufman D.M., Kerr J.T., Mittelbach G.G., Oberdorff T., O'Brien E.M., Porter E.E. \& Turner J.R.G. (2003). Energy, water, and broad-scale geographic patterns of species richness. Ecology, 84, 3105-3117.

Hawkins B.A. \& Porter E.E. (2003). Relative influences of current and historical factors on mammal and bird diversity patterns in deglaciated North America. Global Ecology and Biogeography, 12, 475-481.

Hijmans R.J., Cameron S. \& Parra J. (2004). WorldClim, version 1.2. A square kilometer resolution database of global terrestrial surface climate.

URL http://biogeo.berkeley.edu/

Hillebrand H. (2004). On the generality of the latitudinal diversity gradient. American Naturalist, 163, 192-211.

Hurlbert A.H. (2004). Species-energy relationships and habitat complexity in bird communities. Ecology Letters, 7, 714-720. 
Jetz W. \& Rahbek C. (2002). Geographic range size and determinants of avian species richness. Science, 297, 1548-1551.

Kaspari M., O'Donnell S. \& Kercher J.R. (2000). Energy, density, and constraints to species richness: ant assemblages along a productivity gradient. The American Naturalist, 155, 280-293.

Kaspari M., Ward P.S. \& Yuan M. (2004). Energy gradients and the geographic distribution of local ant diversity. Oecologia, 140, 407-413.

Kaspari M., Yuan M. \& Alonso L. (2003). Spatial grain and the causes of regional diversity gradients in ants. Am. Nat., 161, 459-477.

Kreft H. \& Jetz W. (2007). Global patterns and determinants of vascular plant diversity. Proceedings of the National Academy of Sciences of the United States of America, 104, 5925-5930.

Majer J.D., Kitching R.L., Heterick B.E., Hurley K. \& Brennan K.E.C. (2001). NorthSouth patterns within arboreal ant assemblages from rain forests in Eastern Australia. Biotropica, 33, 643-661.

McGlynn T.P., Salinas D.J., Dunn R.R., Wood T.E., Lawrence D. \& Clark D.A. (2007). Phosphorus limits tropical rain forest litter fauna. Biotropica, 39, 50-53.

Mittelbach G.G., Schemske D.W., Cornell H.V., Allen A.P., Brown J.M., Bush M.B., Harrison S.P., Hurlbert A.H., Knowlton N., Lessios H.A., McCain C.M., McCune A.R., McDade L.A., McPeek M.A., Near T.J., Price T.D., Ricklefs R.E., Roy K., Sax D.F., Schluter D., Sobel J.M. \& Turelli M. (2007). Evolution and the latitudinal diversity gradient: speciation, extinction and biogeography. Ecology Letters, 10, 315-331.

Montoya D., Rodriguez M.A., Zavala M.A. \& Hawkins B.A. (2007). Contemporary richness of holarctic trees and the historical pattern of glacial retreat. Ecography, 30, 173-182.

Moreau C.S., Bell C.D., Vila R., Archibald S.B. \& Pierce N.E. (2006). Phylogeny of the ants: Diversification in the age of angiosperms. Science, 312, 101-104.

Morton S.R. \& Davidson D.W. (1988). Comparative structure of harvester ant communities in arid Australia and North America. Ecological Monographs, 58, 19-38.

Pautasso M. \& Gaston K.J. (2005). Resources and global avian assemblage structure in forests. Ecology Letters, 8, 282-289.

Peeters C. \& Ito F. (2001). Colony dispersal and the evolution of queen morphology in social Hymenoptera. Annual Review of Entomology, 46, 601-630.

Platnick N.I. (1991). Patterns of biodiversity: tropical versus temperate. Journal of Natural History, 25, 1083.

Qian H., Ricklefs R.E. \& White P.S. (2005). Beta diversity of angiosperms in temperate floras of eastern Asia and easter North American. Ecology Letters, 8, 15-22.

Rex M.A., Stuart C.T., Hessler R.R., Allen J.A., Sanders H.L. \& Wilson G.D.F. (1993). Global-scale latitudinal patterns of species-diversity in the deep-sea benthos. Nature, 365, 636-639.

Ricklefs R.E., Qian H. \& White P.S. (2004). The region effect on mesoscale plant species richness between eastern Asia and eastern North America. Ecography, 27, 129136. 
Page 30 of 30

144 Rodriguero M.S. \& Gorla D.E. (2004). Latitudinal gradient in species richness of the New World Triatominae (Reduviidae). Global Ecology and Biogeography, 13, $75-84$.

Rohde K. (1999). Latitudinal gradients in species diversity and Rapoport's rule revisited: a review of recent work and what can parasites teach us about the causes of the gradients? Ecography, 22, 593-613.

Sanders N.J., Lessard J.P., Fitzpatrick M.C. \& Dunn R.R. (2007). Temperature, but not productivity or geometry, predicts elevational diversity gradients in ants across spatial grains. Global Ecology and Biogeography, 16, 640-649.

Shattuck S.O. (1999). Australian ants: their biology and identification. CSIRO, Collingwood, Vic.

Sinclair B.J. \& Chown S.L. (2005). Climatic variability and hemispheric differences in insect cold tolerance: Support from southern Africa. Functional Ecology, 19, 214221.

Svenning J.C. \& Skov F. (2005). The relative roles of environment and history as controls of tree species composition and richness in Europe. Journal of Biogeography, 32, 1019-1033.

Ting S., S. Hartley \& Burns K.C. (2008). Global patterns in fruiting seasons. Global Ecology and Biogeography, 17, 648-657.

Wilf P., Labandeira C.C., Johnson K.R. \& Cuneo N.R. (2005). Richness of plant-insect associations in eocene patagonia: A legacy for south American biodiversity. Proceedings of the National Academy of Sciences of the United States of America, 102, 8944-8948.

Willig M.R., Kaufman D.M. \& Stevens R.D. (2003). Latitudinal gradients of biodiversity: Pattern, process, scale, and synthesis. Annual Review of Ecology Evolution and Systematics, 34, 273-309.

Woodward F.I. (1987). Climate and plant distribution. Cambridge University Press, Cambridge.

Zachos J., Pagani M., Sloan L., Thomas E. \& Billups K. (2001). Trends, rhythms, and aberrations in global climate 65 Ma to present. Science, 292, 686-693. 